\title{
CONSERVAÇÃO E GERMINAÇÃO DO PÓLEN, POLINIZAÇẢO E FRUTIFICAÇÃO EFETIVA EM PESSEGUEIROS E NECTARINEIRAS SUBTROPICAIS (')
}

\author{
WILSON BARBOSA $2 \%$, FERNANDO ANTONIO CAMPO-DALL'ORTO 2.5 , \\ MÁRIO OJIMA ( $\%$, FERNANDO PICARELLI MARTINS (\%) \\ - YONE MANGILU SELUTO BOAVENTURA (9)
}

\begin{abstract}
RESUMO
Pesquisaram-se ambientes, períodos de conservaçäo e meios de cultura para germinaçāo do pólen, além de frutificaçāo ofetiva sob autopolinização e polinizaçäo aberta em 25 cultivares e seleçōes de pessegualros e nectarineiras do Banco de Germoplasma do Instituto Agronómico (IAC). Os pólens conservados em dessecador a $0 \pm 1^{\circ} \mathrm{C}$ mantiveram por 60 dies altes taxas de germinaçäo (acima de $70 \%)$. Em amblente de laboratório $\left(25 \pm 2^{\circ} \mathrm{C}\right)$, o pólen perdeu rapidamente sua viabilidade; após $03^{0}$ dia de armazenamento, o vigor germinativo diminuiu progressivamente. A melhor germinaçāo do pólen in vitro (89\%) ccorreu em meio contendo solução sallna de Murashige \& Skoog, sacarose 5\% - ágar $0,7 \%$. Os cultivares e seleçōes analisados mostraram-se autoférteis, excetuando-se a nectarina IACN1574-25, que apresentou a caracteristica genética da androesterilidade. As altas frutificaçöes efetivas, tanto sob autopolinizaçāo quanto polinizaçāo livre (> 50\%), forarn obtidas pelos cultivares Jóia-1, Ouromel-3, Aurora-1, Aurora-2 e Flordaprince híbridos IAC 680-13 \& IAC 680-178.
\end{abstract}

Termos de indexaç̧̌o: péssego, nectarina, Prunus persica, perminaçâo do pólen in vitro; autopolinizaçäo; pollnizaçáo aberta; frut́ficaçăo; androesterilidade, autofertilidade.

\section{ABSTRACT \\ POLLEN STORAGE AND GERMINATION, POLLINATION AND FRUIT SET IN SUBTROPICAL PEACHES AND NECTARINES}

Subtropical peaches and nectarines pollen storage, germination and fruit set were studied. The results showed that the pollen stored in a desiccator at $0 \pm 1^{\circ} \mathrm{C}$ maintained high germination rates - over $70 \%$ - for 60 days; under room temperature

(') Pesquisa realizada com subsídio parcial do CNPq, da FAPESP • do FIPEC, dentro do projeto IAC: "Manutençāo de germoplasma de frutíferas de clima temperado". Recebido para publicaçäo em 21 de maio - aceito em 27 de dezembro do 1990.

(2) Seçāo de Fruticultura de Clima Temperado, Instituto Agronômico (IAC). Caixa Postal 28, 13001 Campinas, SP.

(3) Estação Experimental de Jundiaí, IAC.

(7) Seçăo de Citologia, IAC.

( $)$ Com bolsa de pesquisa do CNPq. 
$\left(25 \pm 2^{\circ} \mathrm{C}\right)$ the pollen lost rapidly their viability after the 3 th day of storage. The best in vitro pollen germination - $89 \%$ - occurred on nutrient media of Murashige \& Skoog, $5 \%$ sacarose and $0,7 \%$ agar. The highest percentages of fruit set - over $50 \%$ - were obtained by Jóia-1, Ouromel-3, Aurora-1, Aurora-2, Flordaprince cultivars and IAC 680-13 and IAC 680-178 hybrids. The male sterility was observed in the IAC N 157425 nectarine.

Index terms: peach, nectarine, Prunus persica, pollen; fruit set; male-sterility; self-fertility; pollination.

\section{INTRODUÇÃO}

A polinização e a fertilização são processos biológicos essenciais à frutificaçăo do pessegueiro. Na sua ausência, sucede a abscisão do fruto, visto que nesta cultura năo ocorrem naturalmente os fenômenos da partenocarpia e da apomixia. Ofruto somente se desenvolve a partir da embriogênese, quando se inicia a síntese local dos reguladores de crescimento. Daí dizer-se que a polinização-fertilizaçāo ser um elo dos mais importantes na cadeia reprodutiva de uma planta, pois deste depende toda a produção frutífera (GREULACH, 1973; WESTWOOD, 1978; MONET, 1983; BARBOSA et al., 1990).

Nesse contexto, as pesquisas sobre conservaçăo e germinaçăo do pólen e sobre frutificação são indispensáveis ao melhoramento genético do pessegueiro e, consequentemente, à própria evolução de sua cultura. Em trabalhos de polinizaçōes controladas de pêssegos e nectarinas, há, normalmente, o requerimento de razoável quantidade de pólen viável para uso imediato. Isso, porém, nem sempre é possível devido à rápida inviabilizaçāo polínica, causada por inadequada armazenagem. Tal fato tem estimulado os melhoristas à procura de métodos efetivos para a conservação do pólen de espécies frutíferas, por longos períodos (KING \& HESSE, 1938; PARFITT \& ALMEHDI, 1984; CAMPO-DALL'ORTO et al., 1985). Em decorrência da necessidade de estocagem de pólen, tomou-se obrigatória a verificaçāo periódica de sua viabilidade; assim, foram desenvolvidos testes (OBERLE \& WATSON, 1953; MEDEIROS, 1979; WERNER \& CHANG, 1981; PARFITT \& GANESHAN, 1989), observando-se, no entanto, pouco consenso quanto ao melhor procedimento.

Afora sua importância nos trabalhos de hibridaçōes artificiais, a polinologia contribui na deteç̧āo de híbridos androestéreis e de baixa fertilidade, ambos indesejáveis à persicultura (BARBOSA et al., 1983). Além disso, o conhecimento das peculiaridades polínicas de um cultivar pode fornecer subsídios à execuçáo de algumas práticas culturais, a exemplo da poda de inverno; neste caso, dependendo do potencial de polinização e de frutificaçāo do pessegueiro, poderá manter-se maior ou menor quantidade de ramos com gemas floriferas (BASSOLS, 1980).

No presente trabalho, investigaram-se os métodos de conservação e de germinaçāo do pólen in vitro, além do potencial de polinizaçăo e de frutificaçāo em 
diversos cultivares e seleçōes de pessegueiros e nectarineiras do Banco de Germoplasma do IAC.

\section{MATERIAL E MÉTODOS}

A experimentação foi realizada no período de junho a setembro de 1985, em pessegueiros e nectarineiras do Banco de Germoplasma da Estaçăo Experimental de Jundiaí $\left(23^{\circ} 08^{\prime} S\right)$, do IAC. Utilizaram-se três plantas de cada um dos 25 cultivares e seleçōes, os quais foram escolhidos de forma a abranger diferentes origens, tipos de frutos e faixas de maturação. Desses cultivares, os obtidos pelo IAC foram os seguintes: Jóia-1, Tropical, Ouromel-3, Dourado-1, Aurora-1, Aurora-2, Delicioso Precoce, Talismā, Bolāo, Régis, Josefina, Centenária, Setembrino, IAC 680-178, IAC 680-13, IAC 180-58 e IAC N 1574-25; pela Universidade da Flórida, EUA: Maravilha, Flordaprince, Fla. 7-3 e Fla. 6-3; pelo Centro Naclonal de Pesquisas de Fruteiras de Clima Temperado, Pelotas, RS: Premier, Precocinho e Sulina, e pelos truticultores de São Paulo: Rei da Conserva.

\subsection{Biologia floral e polínica}

Para os testes preliminares de conservação e de germinaçáo de pólen, coletaram-se, ao acaso, para cada um dos cultivares: Talismă, Jóia-1, Josefina e Rei da Conserva, 200 flores em botāo, chamado de estádio $E$ ou balăo (BARBOSA et al., 1990a), das quais se retiraram duas amostras de pólen.

A primeira amostra destinou-se aos testes preliminares de otimizaçāo de meios de cultura para germinação do pólen in vitro. Para tanto, experimentaram-se os seguintes meios: (1) soluçāo salina de MURASHIGE \& SKOOG (1962) (MS) e sacarose a 5, 10, 15 e 20\%; (2) MS e glicose a 5, 10, 15 e 20\%, e (3) sacarose a $5 \%$ e $\mathrm{H}_{3} \mathrm{BO}_{3}$ (ácido bórico), a $0,1,0,01$ e $0,001 \%$. Ágar a $0,7 \%$ e $\mathrm{pH} 6,5$ foram constantes nos três meios experimentados.

Com a segunda amostra, efetuaram-se os testes preliminares de conservação do pólen, que foi armazenado em ambiente de laboratório $\left(25 \pm 2^{\circ} \mathrm{C}\right)$ e em dessecador a trio $\left(0 \pm 1^{\circ} \mathrm{C}\right)$, dentro de frascos escuros, por 90 dias. A viabilidade do pólen foi acompanhada periodicamente pela germinação in vitro; esse acompanhamento foi diário, durante a primeira semana de armazenamento, e depois quinzenal, até completar o período de três meses.

Após a determinação dos métodos adequados à conservação e à germinaçāo do pólen, coletaram-se, ao acaso, 100 flores em botão (estádio $\mathrm{E}$ ), de cada um dos 25 cultivares utilizados na pesquisa. Todo o material foi avaliado quanto: ao tipo de flor; ao número de anteras por flor e grãos de pólen por antera e flor, e à germinação do pólen in vitro, seguindo-se os métodos descritos por BARBOSA (1989) e BARBOSA et al. (1991). 


\subsection{Polinização e frutificação efetiva}

Analisou-se a capacidade de autopolinização do material através do ensacamento, ao acaso, por dez dias, de 200 flores em botáo por planta. $\mathrm{Na}$ polinização aberta, analisaram-se 400 flores em antese por planta e, após cerca de 45 dias, contaram-se os frutinhos remanescentes nos ramos marcados com etiquetas e estabeleceram-se os índices de frutificação efetiva $(\%)$

Aos dados polínicos e de frutificação efetiva calcularam-se os intervalos de confiança para a média, ao nível de $95 \%$.

\section{RESULTADOS E DISCUSSÃO}

\subsection{Germinaçăo do pólen in vitro}

Altos índices de germinação, 81 a $89 \%$, foram obtidos quando da adição de sacarose $5 \%$ à soluçāo salina MS - Quadro 1. As demais concentraçōes desse açúcar inibiram, em certo grau, a germinaçāo e o crescimento do tubo polínico. Os menores índices de germinaçāo ocorreram nos meios com glicose, sobretudo naqueles com dosagens maiores. A adiçāo de ácido bórico à sacarose $5 \%$ mostrou-se efetiva na germinaçāo do pólen, notadamente do 'Jóia-1' e 'Talismā'. O emprego desse nutriente, sem associação ao MS, não correspondeu à expectativa de p̀ropiciar altos índices de germinaçāo, conforme se verifica em outras espécies (MANN \& WOODBURY, 1969; VÁLIO, 1979).

Tornou-se patente que oMS, composto dos macro-e dos micronutrientes essenciais, associado a uma fonte de carbono, no caso sacarose $5 \%$, constitui a melhor opçāo à germinaçăo do pólen in vitro de pessegueiros e nectarineiras subtropicais. Assim sendo, adotou-se nas demais fases do trabalho o meio de cultura $n^{2} 1$, por proporcionar a melhor taxa de germinaçāo do pólen in vitro (Quadro 1).

\subsection{Conservação do pólen}

Em ambiente de laboratório $\left(25 \pm 2^{\circ} \mathrm{C}\right)$, parte dos grãos de pólen do 'Jóia-1', 'Talismā', 'Rei da Conserva' e 'Josefina' conservaram-se viáveis durante cerca de 30 dias, após o que perderam integralmente o poder germinativo - Quadro 2. Nessas condiçōes, altos índices germinativos (acima de 70\%) foram registrados somente até o terceiro dia de armazenamento. Os grãos de pólen demonstraram, assim, suscetibilidade à temperatura e à umidade relativa do ar elevadas. Presume-se, daí, que em condiçóes de campo os grãos de pólen de pessegueiros subtropicais possuam vida útil bem reduzida.

(9) Trata-se da frutificação definitiva da planta, isenta, praticamente, dos abortos espontâneos de frutos. 


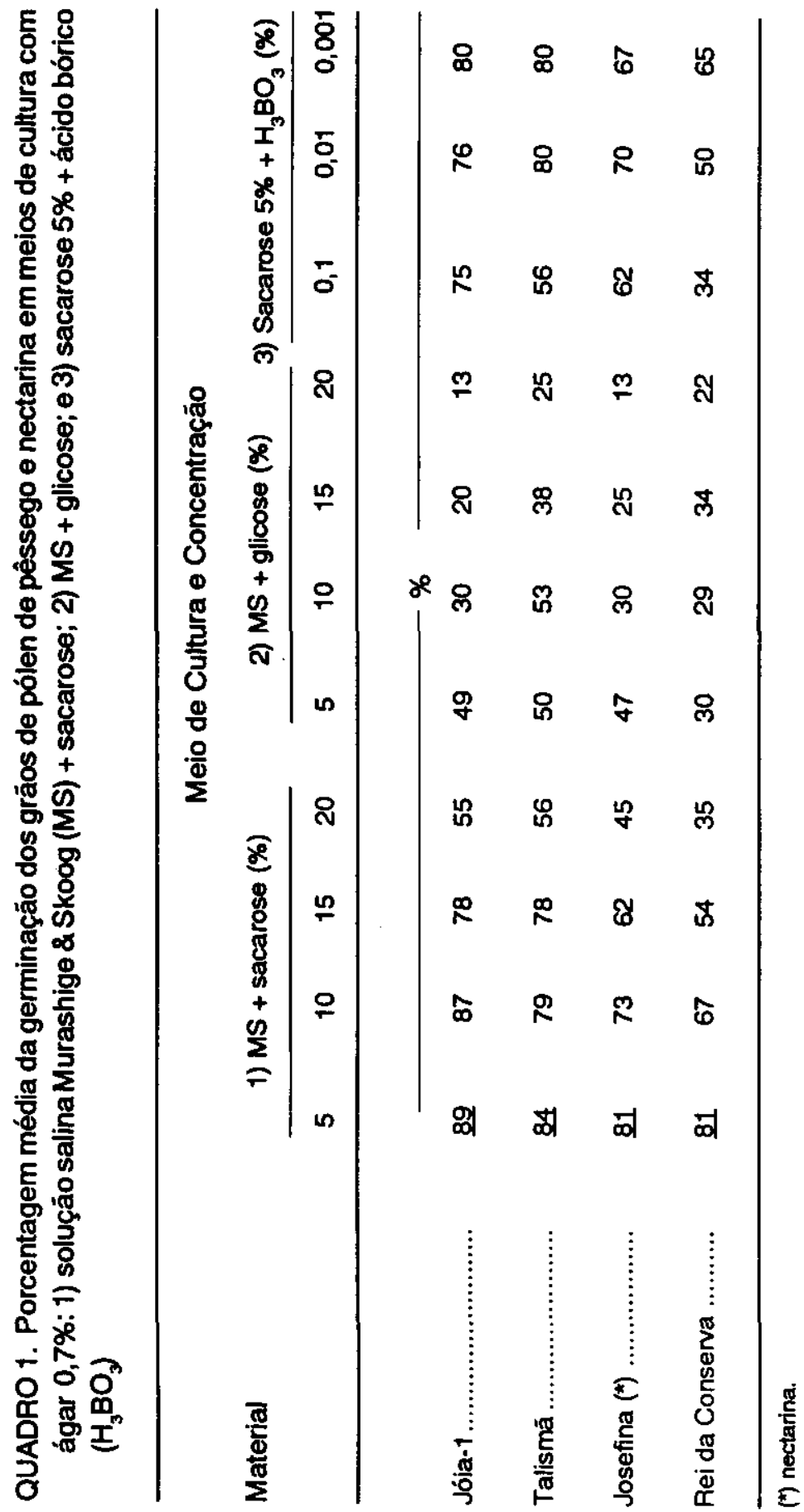




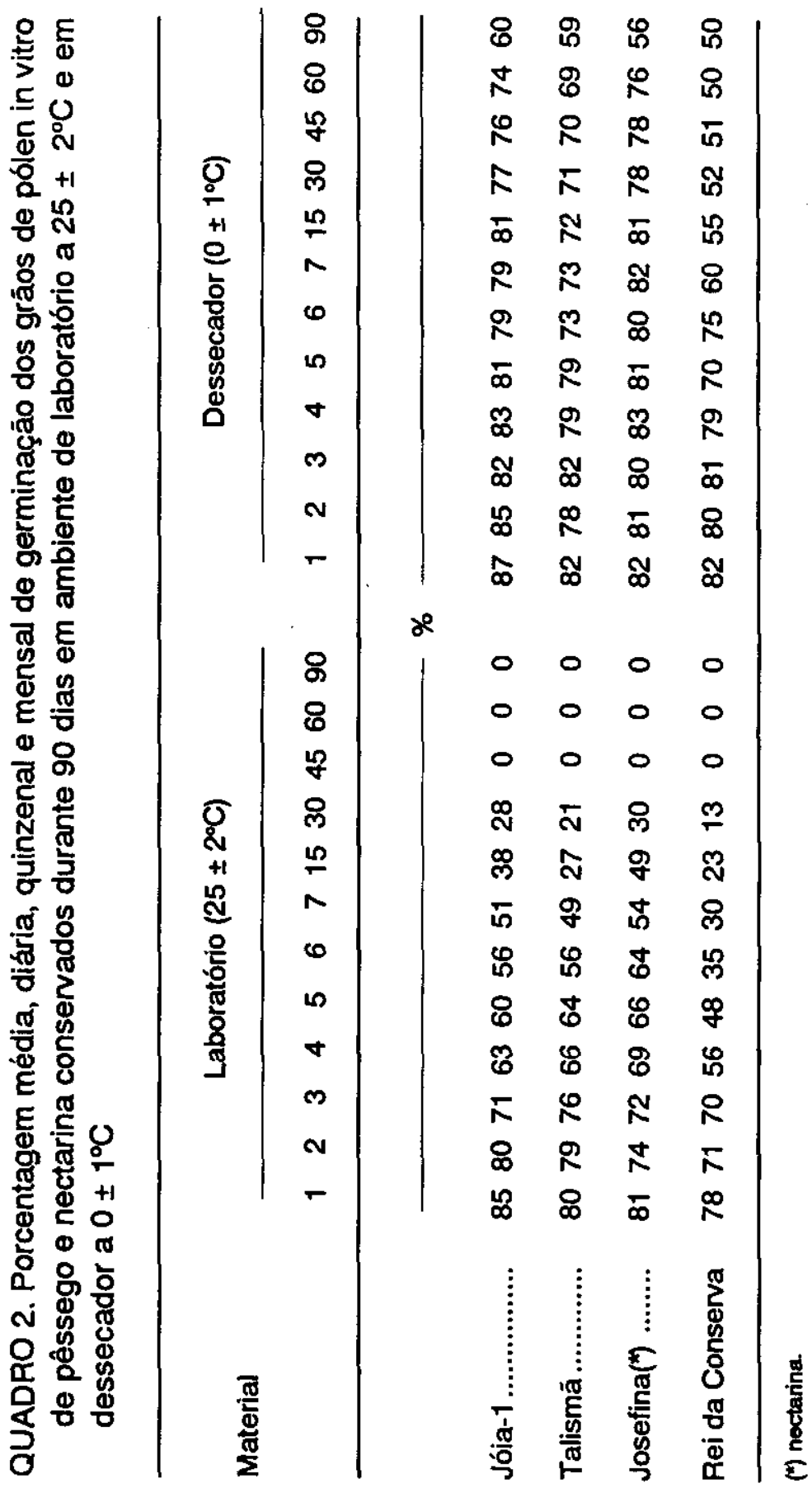


Já em ambiente de dessecador a frio $\left(0 \pm 1^{\circ} \mathrm{C}\right)$, o material conservou-se adequadamente por 60 dias; nesse período, os grāos de pólen mantiveram índices de germinação acima de 70\%. O 'Rei da Consenva' constituiu exceção, mostrando uma queda do poder germinativo do pólen mais acentuada, mesmo assim com $50 \%$ no $60^{\circ}$ dia.

Com 90 dias nesse ambiente, mais de $50 \%$ do material dos quatro cultivares ainda permanecia viável. Por esses dados, verifica-se que o presente método tem importância no armazenamento de pólen de pêssego apenas por breves periodos; apesar de conservado a $0 \pm 1^{\circ} \mathrm{C}$ de temperatura, nota-se progressiva perda de vigor germinativo. Assim, para estudos de conservação de pólen por longos períodos, as temperaturas mais frias nāo devem ser desprezadas. Segundo GRIGGS et al. (1953), o pólen de frutíferas temperadas pode conservar-se razoavelmente a $-18^{\circ} \mathrm{C}$ até por três anos. Pesquisas recentes, entretanto, sugerem o armazenamento de pólen por períodos indefinidos, a-196 $\mathrm{C}$, pelo processo de criopreservaçăo (LEE et al., 1985). Com a evoluçăo deste último método, torna-se perfeitamente exequível o intercâmbio de germoplasmas polínicos, importante para determinados programas de melhoramento genético.

\subsection{Caracterização floral e polínica, polinizaçáo e frutificação efetiva}

Dos 25 cultivares e seleções de pêssegos e nectarinas analisados, somente ofla.7-3 eo'Bolāo' apresentaram flores campanuladas: pétalas pequenas, malformadas, pouco atrativas e róseo-escuras. Os demais exibiram flores rosáceas: pétalas grandes, bem formadas e róseo-claras. Os pêssegos e nectarinas de polpa amarela apresentaram flores com nectário amarelo-escuro e os de polpa branca, nectário amarelo-claro-esverdeado.

O tamanho do pistilo variou de 6 a $15 \mathrm{~mm}$ para os pêssegos e de 14 a $17 \mathrm{~mm}$ para as nectarinas. O número de anteras por flor situou-se na faixa de 34 a 50. 'Rei da Conserva', IAC N 1574-25 e Setembrino apresentaram os limites inferiores: $34,3 \pm 1,6 ; 35,1 \pm 2,3$ e $36,1 \pm 1,9$ anteras por flor respectivamente. Os limites superiores foram verificados em 'Flordaprince', 'Maravilha'e 'Tropical': $50,0 \pm 1,6 ; 49,4 \pm 1,8$ e 46,0 $\pm 1,4$ anteras por flor respectivamente - Quadro 3 .

O número registrado de grăos de pólen por antera pode ser considerado elevado, exceto em Fla. 7-3, Setembrino e IAC N 1574-25. 'Jóia-1', 'Tropical', IAC 180-58, 'Talismā' e 'Maravilha' apresentaram maior abundância polínica, ultrapassando 1.500 grãos de pólen por antera a 67.000 por flor - Quadro 3; esses pêssegos apresentaram altos índices de germinação de pólen, acima de $70 \%$.

$A$ androesterilidade completa foi verificada apenas num material: IAC N 1574-25 $(7)$. Esta nectarina, apesar de produzir cerca de 10 grăos de pólen por

(7) Híbrido do cruzamento Nectar x Sunlite, possui polpa branca e alta qualidade organoléptica. 


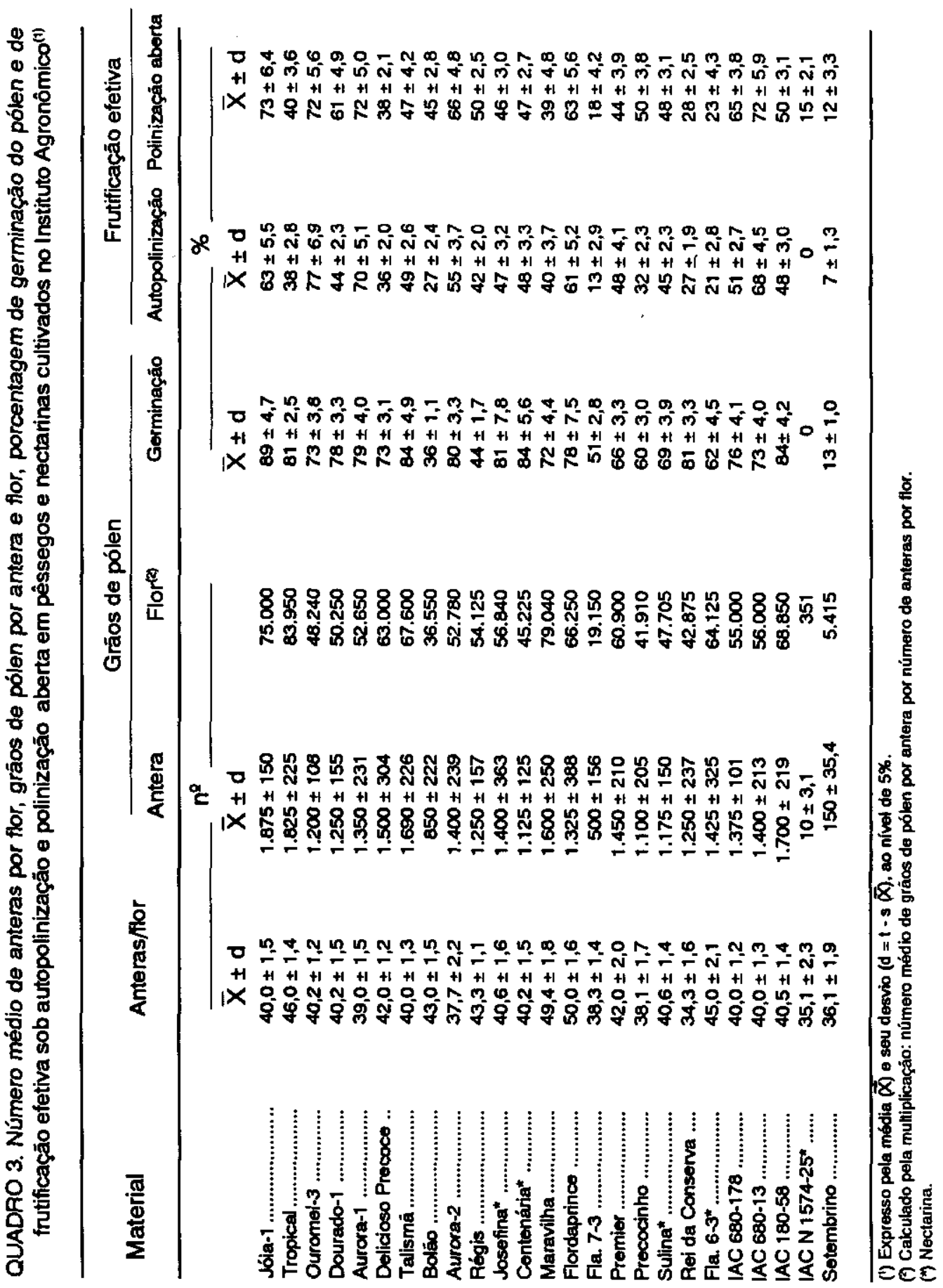


antera, apresentou-se completamente infértil; a germinação do pólen e a autopolinização foram nulas. Suas flores, ao receber pólen de outros cultivares, em polinizaçāo aberta, proporcionaram frutificaçōes de $15 \%$ apenas. Com tal comportamento reprodutivo, essa nectarina pode ser considerada inapta à cultura comercial. Essa anomalia, de caráter genético simples e recessivo, foi relatada pela primeira vez na década de 20, para o pêssego cv.J. H. Hale e, posteriormente, para Chinese cling, June Elberta, Hiley Belle e outros $\left({ }^{(}\right)$.

O Setembrino, apresentando 150 grăos de pólen por antera, com $13 \%$ de germinação e frutificaçōes efetivas de 7 e 12\%, respectivamente, em autopoliniżaçáo e polinizaçăo aberta, poderia ser classificado como pêssego de baixa fertilidade. Tal como a nectarina IAC N 1574-25, constitui material impróprio ao cultivo comercial. Essas duas seleçōes, utilizadas como plantas-mães receptoras de pólen, em cruzamentos artificiais, raramente proporcionam frutificaçōes acima de $10 \%\left({ }^{\circ}\right)$.

O comportamento reprodutivo irregular deFla.7-3 deve-se, provavelmente, à baixa adaptaçăo ao clima subtropical da regiāo de Jundiaí, que possui cerca de 50 horas anuais de frio abaixo de $7,2^{\circ} \mathrm{C}$. No local de origem, Flórida, EUA, esse material parece florescer e frutificar-se normalmente (RODRIGUEZ \& SHERMAN, 1985).

Os demais pêssegos e nectarinas frutificaram abundantemente, tanto em autopolinização natural quanto em polinizaçāo livre. Os mais prolíferos foram: 'Jóia-1', 'Ouromel-3', 'Aurora-1', 'Aurora 2', 'Dourado-1', 'Flordaprince', IAC 680-13 e IAC 680-178 (Quadro 3). Daí afirmar-se que, em pessegueiros autoférteis, ser desnecessário o uso de interpolinizantes nas linhas de cultivo.

Ressalte-se a importância dos altos índices de frutificaçōes efetivas, pois proporcionam maior quantidade de pêssegos nos ramos. O 'Tropical' 'por exemplo, com frutificaçóes efetivas de $40 \%$, exibe em suas plantas cerca de 40 frutos por metro de ramo (BARBOSA et al., 1989); com tal prolificidade, permite uma seleção homogênea de frutos na ocasiăo da prática cultural do raleio.

\section{CONCLUSÕES}

1. A melhor germinação do pólen in vitro de pessegueiros e nectarineiras subtropicais foi obtida no meio de cultura composto da solução salina de Murashige \& Skoog, $5 \%$ de sacarose e $0,7 \%$ de ágar. Nessas condiçōes, obtiveram-se germinaçōes até de $89 \%$ dos grāos de pólen.

(9) G. BARGIONI, Androsterilità del pesco 'Aurora'. Verona, Istituto Sperimentale di Frutticoltura, s.d. $5 p$.

(9) W. BARBOSA. Melhoramento genético e cultural de frutiferas de clima temperado: 1 . Obtenção de cultivares em diversas épocas de maturaçäo. II. Desenvolvimento das técnicas de cultura in vitro. Campinas, Instituto Agronômico. Relatórios ao CNPq de 1983 e 1984 (não publicados). 
2. Em ambiente de dessecador $\mathrm{a} 0 \pm 1^{\circ} \mathrm{C}$ de temperatura, a viabilidade do pólen conservou-se durante 60 dias ao nível de $70 \%$. Em ambiente de laboratório a $25 \pm 2^{\circ} \mathrm{C}$, esse nível foi mantido até o $3^{\circ}$ dia de armazenamento; após esse período, o pólen apresentou perda progressiva do vigor germinativo, até que a germinação se tornou nula ao redor do $45^{\circ}$ dia.

3. Dos 25 cultivares e seleçōes pesquisados, somente a nectarina IAC N 1574-25 apresentou a característica de androesterilidade, e o pêssego Setembrino, baixa fertilidade; os demais mostraram-se férteis, independentemente do tipo de polinizaçāo efetuada. As melhores frutificaçōes efetivas foram obtidas pelos pêssegos 'Jóia-1', 'Ouromel-3', 'Aurora-1' e 'Aurora 2', 'Flordaprince', IAC 680-13 e IAC 680-178.

\section{AGRADECIMENTOS}

Os autores agradecem aos Srs. José de Camargo Barros e Antonio Marcos Luize, da Estaçăo Experimental de Jundiaí, os tratos culturais do pomar, e à Pesquisadora Científica Neuza Diniz da Cruz da Seção de Citologia, as sugestōes ao trabalho.

\section{REFERÊNCIAS BIBLJOGRÁFICAS}

BARBOSA, W. Desenvolvimento vegetativo e reprodutivo do pessegueiro em pomar compacto sob poda drástica anual. Piracicaba, ESALQ, 1989. 154p. Dissertação de Mestrado.

; CAMPO-DALL'ORTO, F.A. \& OJIMA, M. Aspectos reprodutivos das fruteiras de clima temperado, objetivando o melhoramento genético. OAgronômico, Campinas, 35:15-20, 1983.

desenvolvimento vegetativo e reprodutivo do pessegueiro em região subtropical. Campinas, Instituto Agronômico, 1990. 37p. (Documentos IAC, 17.)

; OJIMA, M.; CAMPO-DALL'ORTO, F.A.; RIGITANO, O.; MARTINS, F.P.; CASTRO, J.L. \& SANTOS, R.R. .'Tropical': novo pêssego de coloraçāo vermelho intensa e bem precoce para São Paulo. In: CONGRESSO BRASILEIRO DE FRUTICULTURA, 10., Fortaleza, 1989. Resumos. Fortaleza, Sociedade Brasileira de Fruticultura, 1989 , p.57.

$O$ pessegueiro no sistema de pomar compacto: ll. Influência das épocas de poda drástica no desenvolvimento das plantas. Campinas, Instituto Agronômico, 1991. 26p. (Boletim científico, 22.) 
BASSOLS, M. do C. M. Frutificação efetiva, germinaçáo do pólen e número de grãos de pólen por antera em pessegueiro. Pelotas, EMBRAPA, UEPAE de Cascata, 1980. 3p. (Pesquisa em andamento, 2)

CAMPO-DALL'ORTO, F.A.; BARBOSA, W.; OJIMA, M. \& CAMPOS, S.AF. de. Análise do pólen em dezoito cultivares demacieira. Bragantia, Campinas, 44(1):421-427, 1985.

GREULACH, V.A. Plant function and structure. New York, MacMillan, 1973. 575p.

GRIGGS, W.H.; VANSELL, G.H. \& IWAKIRI, B.T. The storage of hand-collected and beecollected pollen in ahomefreezer. Proceedings of the American Society for Horticultural Science, Ithaca, 62:304-305, 1953.

KING, J.R. \& HESSE, C.O. Pollen longevity studies with deciduous fruits. Proceedings of the American Society for Horticultural Science, Ithaca, 36:310-313, 1938.

LEE, C.W.; THOMAZ, J.C. \& BUCHMANN, S.L. Factors affecting in vitro germination and storage of jojoba pollen. Journal of the American Society for Horticultural Science, New York, 110(5):671-676, 1985.

MANN, L.P. \& WOODBURY, G.W. The effect of flower age, time of day and variety on pollen germination of onion, Allium cepa $\mathrm{L}$. Journal of the American Society for Horticultural Science, New York, 94:102-104, 1969.

MEDEIROS, A.R.M. Ełeito da temperatura controlada na germinaçăo dos grăos de pólen e crescimento do tubo polínico em pessegueiro (Prunus persica (L.) Batsch). In: CONGRESSO BRASILEIRODEFRUTICULTURA, 5., Pelotas, 1979. Anais. Pelotas, Sociedade Brasileira de Fruticultura, 1979. v.2, p. 407-416.

MONET, R. Le pêcher: génétique et physiologie. Paris, INRA et Masson, 1983. 133p.

MURASHIGE, T. \& SKOOG, F. A revised medium for rapid growth and bioassays with tobacco tissue cultures. Physiologia Plantarum, Copenhagen, 15(3):473-497, 1962.

OBERLE, G.D. \& WATSON, R. The use of 2, 3,5-triphenyl tetrazolium chloride in viability tests of fruit pollens. Proceedings of the American Society for Horticultural Science, Ithaca, 61:299-303, 1953.

PARFITT, D.E. \& ALMEHDI, A.A. Liquid nitrogen storage of pollen from five cultivated Prunus species. Hort Science, Alexandria, 19(1):69-70, 1984.

\& GANESHAN, S. Comparison of procedures for estimating viability of Prunus pollen. HortScience, Alexandria, 24(2):354-356, 1989.

RODRIGUEZ, A.J. \& SHERMAN, W.B. Relationships between parental, seed, and seedling chilling requirement in peach and nectarine. Journal of the American Society for Horticultural Science, New York, 110(5):627-630, 1985. 
VÁLIO, I.F.M. Frutificaçāo. In: FERRI, M.G., coord. Fisiologia vegetal. São Paulo, EPU/EDUSP, 1979. v.2, p.313-342.

WERNER, D.J. \& CHANG, S. Stain testing viability in stored peach pollen. HortScience, Alexandria, 16(4):522-523, 1981.

WESTWOOD, M.N. Temperate zone pomology. San Francisco, W.H. Freeman, 1978. $428 \mathrm{p}$. 